\title{
CANDIDATE-SCREENING, INFORMATION TECHNOLOGY AND THE LAW: SOCIAL MEDIA CONSIDERATIONS
}

\author{
Lorrie Willey, Western Carolina University, lwilley@email.wcu.edu \\ Barbara Jo White, Western CarolinaUniversity,whiteb@email.wcu.edu \\ Teri Domagalski, Western Carolina University, tdomagalski@catamount.wcu.edu \\ Janet C. Ford, Western Carolina University, jford@catamount.wcu.edu
}

\begin{abstract}
Traditional hiring practices, specifically vetting the potential candidate's qualifications, have taken an IS turn in the digital age. From posting position announcements, accepting applications, reviewing resumes, scheduling interviews to screening job candidates, the computer has become an integral aspect of the process. But the use of social media, specifically Facebook $\mathrm{TM}$, to screen candidates, has triggered legal concerns for business users as well as obligations on IT to monitor appropriate usage. IT departments, Human Resources and Legal Counsel will increasingly need to work together to develop the organization's social media policies. Recommended steps for social media policy development are included.
\end{abstract}

Keywords: Social Media, Legal Issues, Human Resources

\section{INTRODUCTION}

The Spring of 2012 has seen a firestorm of controversy and outrage over employers' requests for the Facebook usernames and passwords of job candidates. Traditional hiring practices have been transformed by technology, including social media, in the last several decades and are still undergoing a great deal of change. From posting position announcements, accepting applications, reviewing resumes, scheduling interviews to candidate-screening, computer technology has become an integral aspect of the process. Through the end of the 1990s, the systems involved in the recruitment and selection processes were called applicant tracking systems but they are now referred to as e-recruitment systems [26]. A corporate Facebook presence plays a major role in e-recruitment. In fact, Gartner analysts report that, in terms of employee recruitment, corporate websites receive fewer hits than their Facebook sites [19]. A Gartner survey showed that nearly half of the respondents are in the process of integrating social software with their e-recruitment processes. The use of social media in the hiring process has legal implications. Specifically, the use of social media, like Facebook ${ }^{\mathrm{TM}}$, to screen candidates has triggered legal privacy concerns for business users and candidates alike, along with corresponding obligations on IT to monitor appropriate usage.

\section{OVERVIEW OF THE HIRING PROCESS}

Employee selection is an important activity for organizations. Good hiring decisions, along with other human resource practices, leverage organizational competitiveness and performance. The practice of identifying potentially suitable and interested job applicants has undergone substantial changes in the past two decades, largely as a result of advances in technology. Although posted job announcements continue to be the standard practice for notifying internal candidates of job openings within organizations, use of classified ads in news print has moderated with the evolution of computer technology. Employers have increasingly come to rely upon the internet to announce job openings. Typical recruitment strategies today include posting job announcements on company websites, on job board sites such as jobs.com and monster.com, and on social network sites (SNS) such as LinkedIn. These have the dual advantages of being cost effective and casting a wider net for applicants.

The principle aim of screening methods such as job interviews, background checks, and selection tests, is to evaluate the extent to which job applicants possess the requisite knowledge, skills, abilities and other characteristics that are associated with successful job performance. The use of valid, job related screening methods is advantageous for several reasons. First, screening methods have associated costs. For example, job interviews incur human costs when 


\section{Issues in Information Systems \\ Volume 13, Issue 1, pp. 300-309, 2012}

organizational personnel allocate time to the interview process. Financial costs may also be levied in situations where organizations reimburse job applicants for travel-related expenses to an interview location. Second, legal concerns may arise when organizations utilize screening methods which are unrelated to the job, particularly when screening methods have an adverse impact upon members of a group protected by anti-discrimination legislation. Third, faulty hiring decisions create other negative consequences such as diminished productivity, compromised quality, declines in employee morale, and increases in turnover costs. For these reasons, the implementation of screening methods that provide job-relevant information about candidates' potential to competently perform the job are important.

Numerous screening methods are used by organizations for employee selection: (1) resumes and job applications; (2) structured and unstructured interviews; (3) letters of recommendation and telephone reference checks; (4) criminal, credit and driving record background checks; (5) history of criminal conviction; (6) personality tests, cognitive ability tests, work sample proficiency tests, job knowledge tests, tests of psychomotor skills, and integrity tests; and (7) drug testing and medical examinations. The Uniform Guidelines on Employee Selection procedures provide compliance standards for organizations in their use of applicant screening tools [34]. Adherence to these guidelines ensures that selection methods demonstrate either content or criterion-related validity and are reliable predictors of some aspect of future job performance for the position in which the screening methods are utilized. They also provide safeguards against charges of employment discrimination by mitigating the adverse impact of selection procedures.

Two of the more common applicant screening methods are resumes and job interviews. When properly utilized, resumes and interviews convey relevant information about education, work experience, and other qualifications that establish applicant fit for the job in question. Increasingly, these tools are being used to ascertain personality traits associated with job success, in addition to other job-related qualifications [6].

Empirical investigations of the Big Five model of personality have consistently shown that conscientiousness is predictive of job success across a wide range of occupations while other personality traits, such as extroversion and agreeableness, are correlated with success in specific occupational groups [7]. A survey of human resources professionals and hiring managers revealed favorable attitudes toward the inclusion of personality characteristics on applicant resumes [38]. However, the pitfalls associated with self-report measures have led to studies of personality and job performance correlates using observers and other raters. Preliminary findings from recent studies suggest that personality characteristics may be reliably measured by observers who view personal websites [22] and by observers who view SNS such as Facebook [5,21]. These initial findings, while still tentative, suggest the potential advantages of using technology such as SNS for applicant screening. If attributes such as applicant personality traits are discernible from SNS, organizations may be favorably disposed to substitute SNS or complement SNS with other practices such as self-report measures, which are sometimes of questionable reliability, and costly personality tests.

At the same time, the dearth of empirical evidence signals a need to proceed cautiously when using SNS such as Facebook, LinkedIn and Twitter for employment selection. In the absence of research that conclusively establishes the validity of using SNS information to draw conclusions about person-organization fit or applicant employability, there is considerable potential for misuse of information. Use of job irrelevant information is one such problem. Screening out applicants based on photographs which reveal race or age, for example, is fraught with legal consequences $[8,10]$. Another is the variability in the amount and type of information publicly available, which makes standardization across the applicant pool difficult, and results in non-comparable predictor information among candidates vying for the same job [8].

Similar hazards befall other screening methods as well, such as reference checks, criminal background checks, and integrity tests. Reference checks obtained from previous employers and letters of recommendation are prone to impression management bias and inflated presentation of applicants' favorable attributes. Similarly, there is the potential for social desirability bias among applicants who complete integrity tests, while the findings from criminal and credit checks may be construed narrowly and screen out potentially viable applicants [10]. 


\section{Issues in Information Systems}

Volume 13, Issue 1, pp. 300-309, 2012

All of this suggests that there is no single selection tool that is superior in screening job applicants for employment. However, adherence to the procedural standards detailed in the Uniform Guidelines on Employee Selection creates a sound basis for organizations to defend the validity of the screening tools used for employee selection. As social networking sites gain popularity as an applicant-screening method, organizations should proceed with caution by applying the same rigorous validation testing as other screening methods, and developing policies to ensure the ethical and legal application of SNS for employment selection decisions.

\section{THE USE OF INFORMATION SYSTEMS AND SOCIAL MEDIA DURING THE HIRING PROCESSES}

Using social recruitment software during the hiring process, according to Gartner analysts, can reduce costs associated with job board or related agency spending by one third or more [24]. The types of processes that these erecruitment systems facilitate [19] include:

- requisitioning for new hires which includes job descriptions, social media and job board posting and approval workflow;

- acquiring candidates which includes social software referral management, candidate relationship management, candidate screening and assessment, candidate scoring and compliance;

- tracking applicants which includes applicant workflow, correspondence management, interview management, background checking and drug screening, and onboarding

- reporting and using analytics, which includes regulatory and other types of reporting.

To facilitate candidate screening specifically, employers are using Social Network Sites (SNS) like Facebook and LinkedIn according to surveys conducted by CareerBuilder.com [14, 15, 16, 17]. According to Ryan Hunt, CareerBuilder's Corporate Communications Manager, surveys were not published for the years 2010 and 2011 [18]. Use of SNS to screen candidates has risen over $200 \%$ from 12\% in 2006 [18] to 37\% in 2012 [17], though down from a high of 45\% in 2009 [16] (see Figure 1 below).

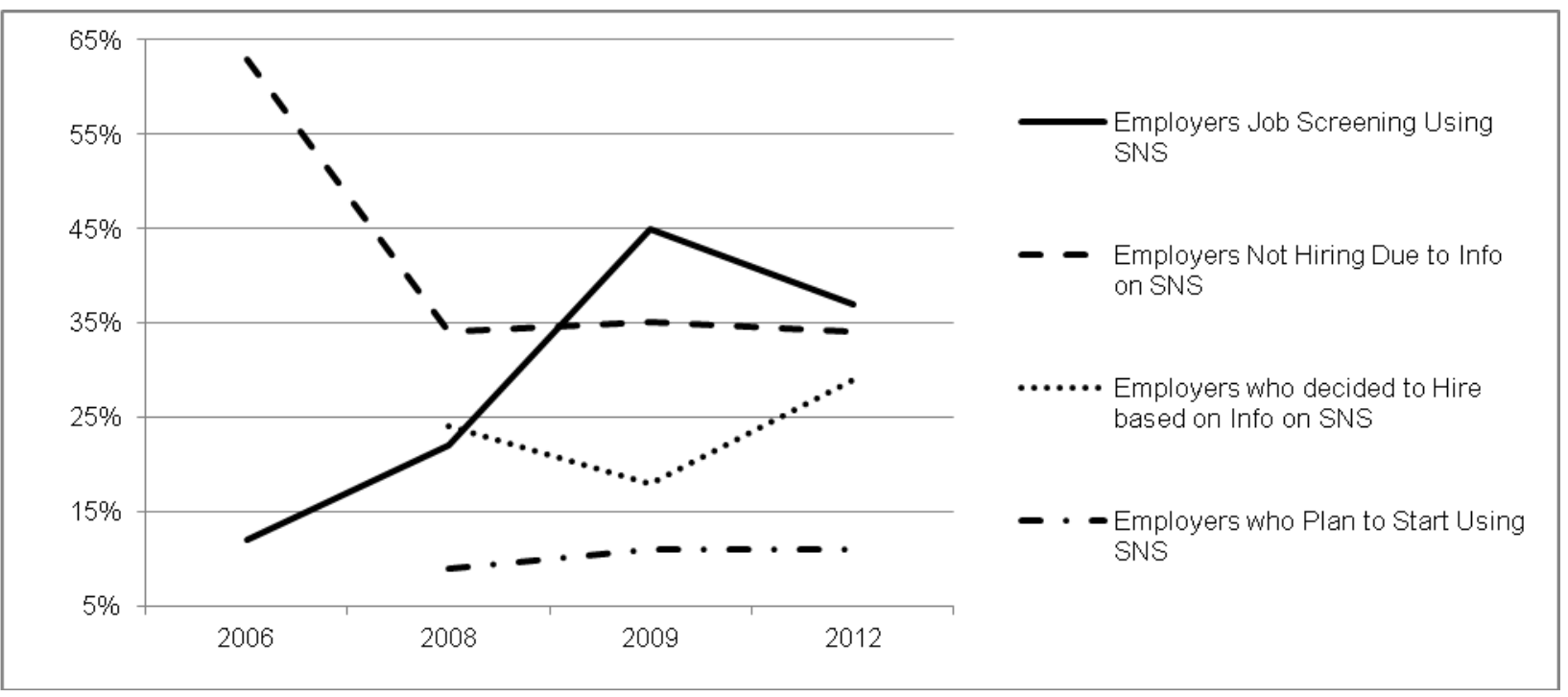

Figure 1. Employer Use of Social Network Sites (SNS) and Its Effect On Hiring Decisions

Employers certainly use information they obtain in order to make a decision to hire candidates. In 2006, nearly two thirds of the hiring managers hired candidates because the background information displayed on social media sites matched the professional qualifications they told employers they had for the job in question [14]. In other words, hiring managers wanted to know if potential candidates were being truthful about their professed qualifications. One fourth to one third of the responding hiring managers were concerned with other issues such as whether they could 


\section{Issues in Information Systems}

Volume 13, Issue 1, pp. 300-309, 2012

tell that the candidate had a wide range of interests, showed creativity, displayed good communication skills or whether others had written good references for the candidate and had good things to say [14].

By 2012, the top reason most of the hiring managers made positive hiring decisions using social media site information was whether they could get a feel for the candidate's personality in order to determine whether the candidate would be a good fit with the company culture. Hiring managers were least likely to hire candidates because they had great references posted about them [17].

The use of SNS to make a positive hiring decision for a candidate has risen from $24 \%$ in 2008 [15] to $29 \%$ in 2012 [17]. Even so, it is still lower than the roughly $35 \%$ of employers who use SNS to reject candidates [15, 16, 17], down from a high of 63\% in 2006 [14] (see Figure 1 on previous page).

CareerBuilder further surveyed hiring managers to find out what they saw on social media sites that caused them to reject candidates (see Figure 2 below). In 2006, nearly a third of all hiring managers surveyed did not hire a candidate because they discovered using social media that the candidate had lied about their qualifications [14]. However by 2012, only one in five hiring managers made a decision to reject a candidate based on whether they lied about their qualifications [17].

In 2012, a greater percentage of hiring managers rejected candidates because of the types of negative information they found on SNS (see Figure 2 below) with nearly half the survey respondents concerned about inappropriate photos or information about candidates drinking or using drugs, which may often be conveyed in inappropriate photos. One third of hiring managers rejected candidates because they saw that candidates had poor communication skills, bad-mouthed fellow employees, previous employers or clients, or used discriminatory remarks [17].

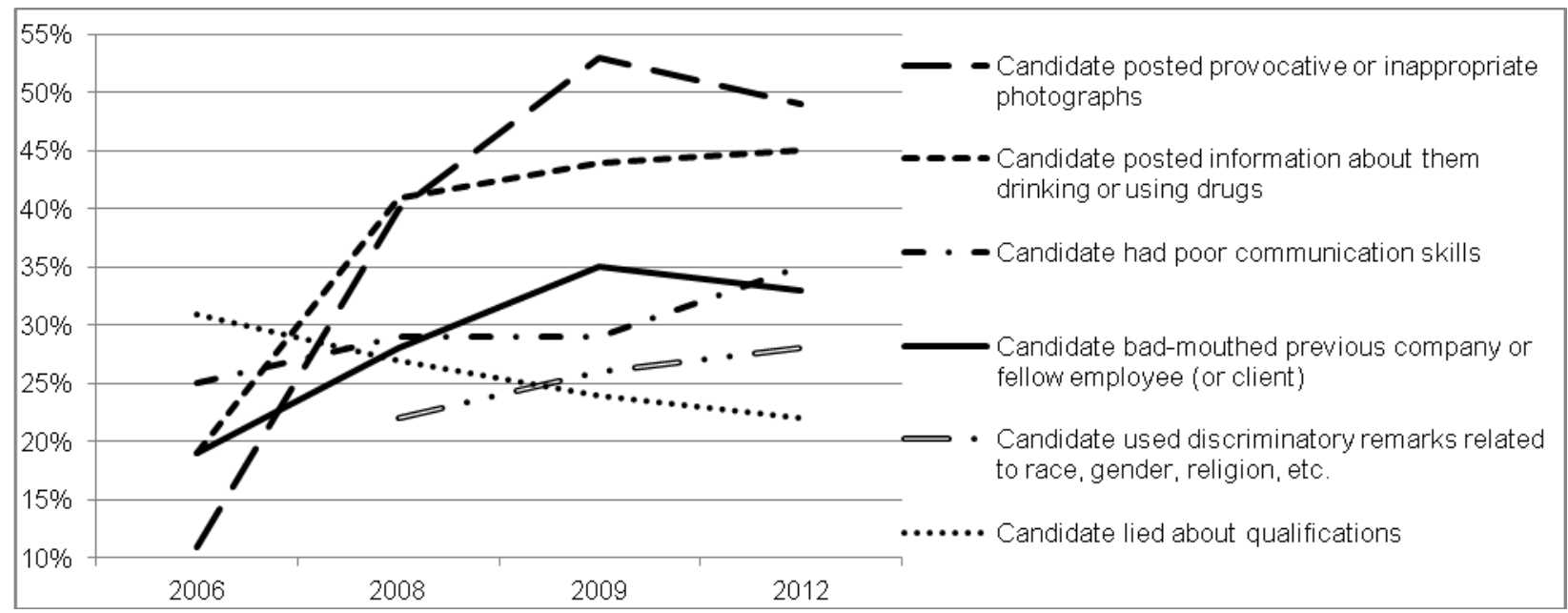

Figure 2. Concerns Found on Social Media that Caused Employers To Reject Candidates

In short, it appears that in 2006, managers tended to hire or not hire candidates on the basis of whether they were telling the truth whereas by 2012 , hiring managers were more concerned with the candidate's ability to make good decisions about what types of information to post in a public place [14, 17]. While some users publicly post photos and other information on social media sites like Facebook, other users have begun keeping that material private or visible only to certain groups. Employers have recently been asking for usernames and passwords in an effort to circumvent a user's privacy settings to gain additional information about a candidate [32]. 


\section{Issues in Information Systems \\ Volume 13, Issue 1, pp. 300-309, 2012}

\section{LEGAL CONCERNS INVOLVING SOCIAL MEDIA CANDIDATE SCREENING}

The rise in the use of social media web sites as a component of the candidate-screening process has not been without some legal red flags. Not only do legal implications compel employers to uncover as much information concerning potential employees as can be reasonably accessed, legal implications also require employers to be cautious in the use of social media sites as a source of that information.

The more information acquired about a candidate, the better for the employer. Failing to make reasonable efforts to ascertain the character and skills of employees can result in liability should poorly-hired employees injure a third party. The civil law tort of negligent hiring places a responsibility on the employer to determine the competence of potential employees. The tort of negligent hiring requires an employer to make reasonable efforts to ensure that an employee will perform his or her duties in a reasonable manner that does not cause harm to others. If an unfit employee harms another, the injured person can sue the employer if it can be proved that the employee was unfit at the time or hire and that the unfitness caused the injury [4]. Liability cannot be avoided by turning a blind eye to possible concerns with applicants; the employer must make reasonable efforts to determine the potential employee's fitness for the job [4].

\section{Employment At-Will and Anti-Discrimination}

When ascertaining the qualifications and abilities of a candidate, any rightfully acquired information is fair game in employment. Workers in the United States are most commonly hired, and fired, based on the employment relationship deemed "at will" [37]. Under that doctrine, employers are free to hire and fire employees at their will, with or without cause. It remains a fundamental tenet of contemporary employment law that employers are free to terminate employees without cause or consequence [37]. When no duration of employment is expressed, both the employer and the employee are free to continue the employment relationship as long as both wish to remain in such a relationship [31]. As a consequence of the at will doctrine, information garnered about a possible employee can be used, or not, in the hiring process in the discretion of the employer. Much of that information is provided by the applicant with the applicant's permission, such as references who will divulge confidential employment information and the applicant's social security number for conducting criminal background checks and credit checks. Requesting access to a SNS appears to be just an extension of the process of providing personal information to potential employers when applying a job.

The primary caveat to the employment at will doctrine lies in United States anti-discrimination laws. The Civil Rights Act of 1964 prohibits employers from making adverse employment decisions based on an applicant's race, color, gender, national origin, religion. Subsequent acts expand the discrimination workplace prohibition to applicants with disabilities [3], to applicants of a certain age [2] and to applicants who are pregnant [27]. Most states also have anti-discrimination laws that mirror the federal laws. Information acquired during candidate screening and used for discriminatory purposes is illegal.

\section{Privacy Laws}

Federal and state governments have also enacted laws to protect job applicants from unjustified intrusions into their privacy. The United States does not have sweeping privacy laws, in fact, privacy laws tend to focus on particular activities and industries [20]. For example, federal law forbids most employers from requiring job applicants to submit to lie detector tests [12]. Employers are also forbidden to discriminate against applicants on the basis of their genetic information, addressing concerns of both privacy and discrimination [13]. Unauthorized access to an applicant's stored electronic communications, which can include postings on social networking sites, or access that exceeds the scope of authorization, may also be unlawful [33].

In addition to the specialized federal privacy laws and similar state laws, state courts have developed a variety of privacy principles that are grouped under the umbrella tort generally referred to as "invasion of privacy." These torts have specific definitions and requirements that must be met for the litigant to successfully pursue her or his case. 


\section{Issues in Information Systems \\ Volume 13, Issue 1, pp. 300-309, 2012}

Moreover, tort law varies from state to state and there is no federal tort law providing national consistency. The individual's ability to sue for the misuse of personal information by a business varies in each state, creating a patchwork of results. Furthermore, the remedies available, such as injunctions or monetary awards would be different from state to state [36].

While several torts can be categorized under the umbrella of "invasion of privacy," two of the most widely recognized privacy torts are intrusion upon seclusion and publicity of private facts. Both of these torts illustrate the legal requirement that the privacy violation be extreme and unreasonable [36]. Intrusion upon seclusion occurs when a person ". . . intentionally intrudes, physically or otherwise, upon the solitude or seclusion of another or his private affairs or concerns ... if the intrusion would be highly offensive to a reasonable person" [29]. The question of determining unreasonableness, private affairs or offensiveness is resolved on a case-by-case basis.

The tort of publicity of private facts involves ". . . giving publicity to a matter concerning the private life of another .. . if the matter publicized is of a kind that (a) would be highly offensive to a reasonable person, and (b) is not of legitimate concern to the public" [29] Since employers typically use the information acquired from social media sites in-house, this would be a very difficult case to make.

The relative paucity of statutory or judicially created protections of privacy in the hiring process leads to uncertainty on the part of both businesses and potential employees over what is or is not protected. Privacy rights are perhaps the most discussed concern in relation to the use of social media pages for pre-hire checks. Constitutional provisions do not necessarily translate to the private sector; and the Fourth Amendment protections against unreasonable searches and seizures apply to governmental actions only [35].

Without a clear legislative directive, a potential employee claiming an invasion of privacy, when asked for social media access information, must establish that s/he possessed an expectation of privacy that met societal norms [1]. Potential employers, however, can argue that the digital generation does not have a high level of privacy expectation. Facebook founder, Zuckerberg, stated "People have really gotten comfortable not only sharing more information and different kinds, but more openly and with more people. That social norm is just something that has evolved over time" [11].

Certainly, posting personal information on a media site that allows access by millions of people severely undermines the privacy argument. In a case involving the use of social media sites for litigation discovery, a New York court determined that since MySpace and Facebook do not guarantee privacy, thus the objecting party had no legitimate expectation of privacy. The party consented to the sharing of Facebook information regardless of the privacy settings [30]. Technologies like Facebook "blur the already elusive lines between the private and the public, the home and the workplace" [1].

\section{Contract Law}

There is also a contractual view of the legalities surrounding the use of Facebook for pre-hire checks. The social media site recently blogged that providing a potential employer with a user name and password violated the terms of use [28]. Facebook's suggestion to job applicants who are asked for username and passwords, is to say no to potential employers [28]. However, contract law does not provide Facebook with any remedy against the potential employer. Under contract law, the potential employer is not a party to the agreement and has no obligations under the contract [25]. Facebook could only enforce its agreements against the user, theoretically by denying the user access to the site. That, in turn, would leave the user seeking a cause of action against the potential employer.

The only clear legal answer lies in the ability of legislative bodies to address the use of social media sites during the employment process. In April of this year, Congressmen Eliot Engle and Jan Schakowsky introduced the "Social Networking Online Protection Act" which would prohibit employers from asking for social media username and passwords [32]. If passed as drafted, employers would face civil penalties up to $\$ 10,000.00$ [32]. While the fate of this bill is unknown, a definitive legislative solution is the best option for clarifying the law in this area. 


\section{Issues in Information Systems \\ Volume 13, Issue 1, pp. 300-309, 2012}

\section{Ethics}

Just as the law remains unsettled as to the legalities involving the use of social media sites in the hiring process, the ethical concerns are also unclear. Certainly, it is incumbent on employers to make all reasonable efforts to hire the most suitable candidates for positions. In that process, information that is considered confidential and private is routinely evaluated. Requested references provide information to prospective employers that would normally be considered confidential. Credit checks, which are becoming a significant factor in the decision to hire, also contain confidential information that the candidate is asked to allow the potential employer access [9]. While the candidate has the option to refuse access, the employer is free to decide against hiring. It could be argued that access to a social media site is comparable to a credit check as it does provide insight to the employer regarding the character of the applicant. If it is ethical to access the financial character of an applicant, it could be argued that access to web sites that provide information as to the personal character of the applicant is also ethical.

\section{Social Media Policy Considerations Involving IT, HR, and Legal Counsel}

IT departments, Human Resources and Legal Counsel will increasingly need to work together to develop the organization's social media policies. Recent political debates at the national and state level will no doubt influence these policies. However, Gartner analyst Jeffrey Mann suggests that corporations not wait on the political process before implementing some common sense guidelines. Mann recommends four simple steps to implement while companies continue to develop more complete policies. The four steps that Mann recommends companies implement include:

1. Extending existing policies (such as confidentiality, intellectual property protection and professional conduct) to the online environment;

2. Providing concrete examples of acceptable and unacceptable online behavior;

3. Alerting employees to particularly sensitive areas and issues such as the sharing of financial, customer or privileged information; and

4. Identifying an in-house resource for employees with social media concerns.[23]

Although these recommendations apply to workplace social media policies in general, each of them is applicable in the hiring process. First on the list is to ensure that HR and IT practices regarding social media sites are consistent with existing policies, such as anti-discrimination and confidentiality. Businesses must be careful to avoid decisions that may appear discriminatory if they are based on social media information that reveals a candidate engaged in protected activity or identifies a characteristic that places the candidate in a protected category. A Facebook posting that identifies a candidate's religious affiliation should not be the basis for refusing to hire that candidate. Confidentiality of information may not seem to be a major concern when businesses obtain that information from a social media site, but there could be situations where the information, although public, should not be repeated outside of the hiring process. Under most existing candidate screening policies, candidates are asked whether they have been convicted of criminal activity. Such information is ordinarily public, yet when it is obtained through the job application process it is often treated as confidential. Information obtained from social media sites should be treated with similar sensitivity. Often, the mere fact that a candidate has applied for a position with a new employer is confidential, and this fact must be shielded from inadvertent disclosure.

Just as there are acceptable and unacceptable forms of conduct in the traditional candidate screening process, there are acceptable and unacceptable online behaviors when using social media to screen candidates. It would be considered unacceptable for an HR representative to impersonate a candidate to a bank or medical care provider in order to obtain confidential information about that candidate. Likewise, misrepresenting oneself online in order to gain access to a candidate's Facebook page should be forbidden. On the other hand, requesting access to a social network site by a candidate who has the option to comply or refuse is both legally permissible and a sound business practice. This, of course, assumes that the information is presently in the public domain. 


\section{Issues in Information Systems \\ Volume 13, Issue 1, pp. 300-309, 2012}

Training employees to recognize situations that involve access to sensitive information and to identify the risks in the disclosure of sensitive information is necessary to ensure that policies developed by the organization are followed. Dissemination of company policies and the means by which to determine whether employees are cognizant of those policies can only be done through a training program. To that end, it is imperative that the organization identify individuals who can provide guidance to employees who are unsure as to the appropriate course of action. Establishing clearly defined policies and providing employee training and support will certainly establish a good faith effort on the part of the organization to handle the information gained from social media sites in a sensitive and legally sound manner.

More specifically, employers will be shielded from legal liability when they provide explicit guidelines to employees about the importance of maintaining confidentiality about proprietary matters that concern financial, product or customer information. Organizations will have additional protections when they require new hires to sign legally-binding agreements that require non-disclosure of proprietary information and/or limit the geographic region in which former employees are permitted to compete with their previous employer.

While the above speaks to newly hired employees, Mann also recommends that organizations provide a resource to current employees who have concerns about the use of social media sites. Although this issue is beyond the scope of this paper, it is a valid concern. In brief, we recommend that organizations give considerable thought to how and when to utilize social network sites which are visited by the members of their workforce. While policies to address such issues are advisable, the newness of this technology for employment purposes is acknowledged. Further direction must await either the legislative or judicial process to provide guidelines on what is acceptable in the employee selection process. In the meantime, we recommend that organizations develop policies and training programs to inform members of their current workforce about the organizational practices that encompass social network sites.

\section{CONCLUSIONS}

Although the correlation between candidates' postings on SNS and their fitness for a job has not been definitively established, the use of SNS as a tool for screening job candidates is an evolving and controversial issue in human resources and IT. In spite of the as-yet untested validity of SNS as a candidate-screening tool, it is evident that many employers are finding SNS useful in providing candidate information that might not otherwise be revealed in the application, interview, or reference-check processes. The trend of employers to consider SNS in making hiring decisions has led to legal and political concerns over employer access to and use of the information posted, primarily due to privacy issues [32]. Both employers and job candidates rely on SNS, but often for cross purposes. IT personnel will be increasingly involved in development of policies and procedures for obtaining and evaluating information from SNS and other social media use, particularly in light of current controversy relating to the use of social media by employers. It is apparent that the utilization of social network sites for applicant screening will continue. Therefore, organizations are well advised to be cognizant of the current state of legislative constraints and anticipate the potential regulatory changes as they craft and implement policies associated with the use of social network sites for the purpose of applicant screening.

\section{REFERENCES}

1. Abril, P. S. (2012). "Blurred Boundaries: Social Media Privacy and the Twenty-first Century Employee," American Business Law Journal, 49. 63.

2. Age Discrimination in the Employment Act of 1967. Available: www.eeoc.gov/laws/statutes/adea.cfm.

3. Americans with Disabilities Act. Available: www.ada.gov/pubs/ada.htm.

4. American Jurisprudence (nd). Employment Relationship, Section 392. Civil Rights Act of 1964. Available: www.eeoc.gov/laws/statutes/titlevii.cfm.

5. Back, M. D., Stopfer, S.V., Gaddis, S., Schmukle, S.C., Egloff, B. \& Gosling, S.D. (2010). Facebook profiles reflect actual personality, not self-idealization. Psychological Science. Available: http://pss.sagepub.com/content/21/3/372. 


\section{Issues in Information Systems \\ Volume 13, Issue 1, pp. 300-309, 2012}

6. Barrick, M. R. \& Mount, M. (1991). The Big Five personality dimensions and job performance: A metaanalysis. Personnel Psychology, 44, 1-26.

7. Barrick, M. R. \& Mount, M. (1993). Autonomy as a moderator between the Big Five personality dimensions and job performance. Journal of Applied Psychology, 78, 111-118.

8. Brown, V. R. and Vaughn, E.D. (2011). The writing on the (Facebook) wall: The use of social networking sites in hiring decisions. Journal of Business and Psychology, 26, 219-225.

9. Burke, D. \& Willey, L. (2008). Employer credit checks and the potential for disparate impact discrimination under Title VII. Business Law Review, 41, 167-188.

10. Davison, H. K., Maraist, C. \& Bing, M.N. (2011). Friend of foe? The promise and pitfalls of using social networking sites for HR decisions. Journal of Business and Psychology, 26, 153-159.

11. Dyer, P. (2010). Facebook’s Zuckerberg: Privacy no longer a "social norm." Available: www.pamorama.net/2010/01/11/facebooks-zuckerberg-privacy-no-longer-a-social-norm.

12. Employee Polygraph Protection Act. Available: www.dol.gov/whd/regs/statutes/poly01.pdf.

13. Genetic Information Nondiscrimination Act. Available: www.eeoc.gov/laws/types/genetic.cfm.

14. Grasz, J. (2006). One-in-four hiring managers have used internet search engines to screen job candidates; onein-ten have used social networking sites, CareerBuilder.com survey finds. Careerbuilder.com. Available: http://www.careerbuilder.com/share/aboutus/pressreleasesdetail.aspx?id=pr331\&ed=12\%2F31\%2F2006\&sd=1 $0 \% 2 \mathrm{~F} 26 \% 2 \mathrm{~F} 2006$.

15. Grasz, J. (2008). One-in-five employers use social networking sites to research job candidates, CareerBuilder.com survey finds. Careerbuilder.com. Available: www.careerbuilder.com/share/aboutus/pressreleasesdetail.aspx $? \mathrm{id}=\mathrm{pr} 459 \& \mathrm{sd}=9 \% 2 \mathrm{~F} 10 \% 2 \mathrm{~F} 2008 \& \mathrm{ed}=12 \% 2 \mathrm{~F} 3$ $1 \% 2 \mathrm{~F} 2008$.

16. Grasz, J. (2009). Forty-five percent of employers use social networking sites to research job candidates, CareerBuilder.com survey finds. Careerbuilder.com. Available:

www.careerbuilder.com/share/aboutus/pressreleasesdetail.aspx $? i d=p r 519 \& s d=8 \% 2 \mathrm{~F} 19 \% 2 \mathrm{~F} 2009 \& \mathrm{ed}=12 \% 2 \mathrm{~F} 3$ $1 \% 2 \mathrm{~F} 2009$.

17. Grasz, J. (2012). Thirty-seven percent of companies use social networks to research potential job candidates, according to new CareerBuilder Survey. Careerbuilder.com. Available: www.careerbuilder.com/share/aboutus/pressreleasesdetail.aspx ?id=pr691\&sd=4/18/2012\&ed=4/18/2099.

18. Ryan Hunt (personal communication, May 8, 2012).

19. Holincheck, J., Otter, T., \& Freyermuth, J. (2012, June 26). Cool vendors in human capital management software. 2012, Gartner, Inc. Available: http://www.gartner.com/id=1996717.

20. Jeskie, S. (2011). Understanding Developments in Cyberlaw. ASPATORE. 2011 WL 3020561.

21. Kluemper, D. H. \& Rosen, P.A. (2009). Future employment selection methods: Evaluating networking web sites. Journal of Managerial Psychology, 24, 567-580.

22. Marcus, B., Machilek, F., \& Scutz, A. (2006). Personality in cyberspace: Personal web sites such as media for personality expressions and impressions. Journal of Personality and Social Psychology, 90, 1014-1031.

23. Mann, J. (2011, May 11). Take four initial steps toward a social media policy, Gartner, Inc. Available: www.gartner.com/id=1664315.

24. Mann, J. (2011, August 25). Hype cycle for business use of social technologies, Gartner, Inc. Available: www.gartner.com/id=1775514.

25. Ochoa v. Ford (1994). Indiana Court of Appeals, 641 N.E. $2 d 1042$.

26. Otter, T., Holincheck, J., \& Freyermuth, J. (2012, June 9). Market guide for e-recruitment solutions, Gartner, Inc. Available: www.gartner.com/id=1919716.

27. Pregnancy Discrimination Act. Available: www.eeoc.gov/laws/statutes/pregnancy.cfm.

28. Quinn, M. (2012). Facebook: Don't ask for passwords. Politico, Available: www.politico.com/news/stories/0312/74395.html.

29. Restatement of Law (Second) Torts, §§ 652B-652E, American Law Institute.

30. Roberts, K. (2010). Court allows discovery of deleted Facebook and MySpace pages. Litigation News, American Bar Association. Available: http://apps.americanbar.org/litigation/litigationnews/top_stories/111610social-networking-discovery-privacy.html.

31. Salt v. Applied Analytical, Inc. (1991). Court of Appeals of North Carolina, 412 S.E. $2 d 97$. 


\section{Issues in Information Systems}

Volume 13, Issue 1, pp. 300-309, 2012

32. Sasso, B. (2012). Lawmakers push bill to ban bosses from asking for Facebook passwords. Available: http://thehill.com/blogs/hillicon-valley/technology/224305-lawmakers-push-bill-to-ban-bosses-from-asking-forfacebook-passwords.

33. Stored Communications Act, 18 U.S.C. $§ \S 2701-2712$. Available: http://uscode.house.gov/uscodecgi/fastweb.exe?search.

34. Uniform Guidelines on Employee Selection Procedures. Available: www.uniformguidelines.com/uniformguidelines.html.

35. US Constitution, 4th amendment.

36. Willey, L. (2006). RFID and consumer privacy: Let the buyer beware," Journal of Legal, Ethical and Regulatory Issues, 10(2), 25-37.

37. Willey, L. (2009). The public policy exception to employment at will: Balancing employers' rights and the public interest," Journal of Legal, Ethical and Regulatory Issues, 12(1), 55-72.

38. Wright, E. W., Domagalski, T. A. \& Collins, R. (2011). Improving employee selection with a revised resume format. Business Communication Quarterly, 74, 272-286. 